\title{
Anthocyanin Derived from Purple Sweet Potato Water Extracts Ameliorated Oxidative Stress, Inflammation, Mechanical Allodynia, and Cold Allodynia among Chronic Constriction Injury-Induced Neuropathic Pain in Rats
}

\author{
I. Putu Eka Widyadharma ${ }^{1,2 *}$, Thomas Eko Purwata ${ }^{1,2}$, Dewa Ngurah Suprapta ${ }^{2,3}$, A. A. Raka Sudewi ${ }^{1,2}$ \\ ${ }^{1}$ Department of Neurology, Faculty of Medicine, Udayana University, Sanglah Hospital, Denpasar, Bali, Indonesia; ${ }^{2}$ Doctoral \\ Program of Biomedical Science, Faculty of Medicine, Udayana University, Denpasar, Bali, Indonesia; ${ }^{3}$ Laboratory of Biopesticide, \\ Faculty of Agriculture, Udayana University, Denpasar, Bali, Indonesia
}

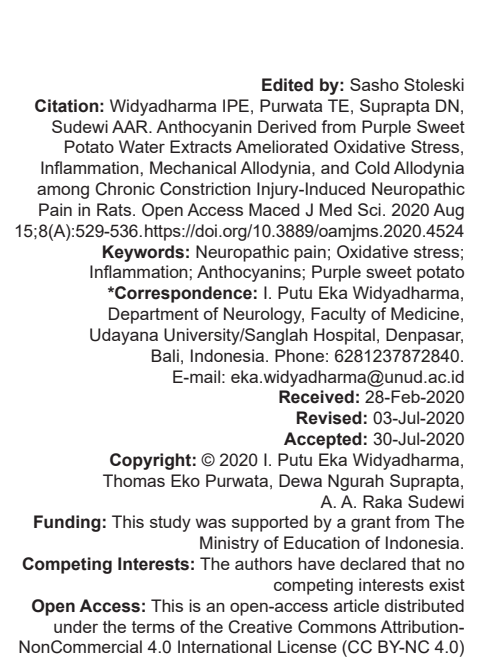

Introduction

Pain, as defined by the International Association for the Study of Pain, is an unpleasant sensory and emotional experience resulting from real or potential tissue injury, or the depiction of its injury. Among various types of pain, neuropathic pain has become a major problem. It is highly prevalent due to its association with various diseases, it exerts negative impacts on physical and social function, thus decreasing patient's quality of life [1].

Neuropathic pain is one of the global challenges. Almost $7-8 \%$ of adult general population suffering of chronic pain has neuropathic pain characteristics, while the number is significantly higher in Indonesia, comprising more than $20 \%$ from general population [2]. In Netherland, neuropathic pain incidences approximately
8 cases/1000 individual each year. A study conducted in German reported that $37 \%$ of patient who comes to visit primary health-care service has suffered low back pain [3]. Neuropathic pain exerts major impact on multiple aspects, affecting not only socio-economically but also emotionally. Chronic neuropathic pain poses a significant correlation with sleep disturbance, emotional, mood, physical function, and social interaction. The negative impact of neuropathic pain of all those aspects will result in depression and low quality of life [4], [5]. Current pharmacologic treatment such as opioids, antidepressants, anticonvulsants, topical analgesics, NMDA receptor antagonists, baclofen, local anesthetics, and clonidine has so far been unable to give satisfactory result [6].

The pathophysiology of neuropathic pain is complex and the entire mechanism is not yet understood [7]. The undertreated peripheral nerve injury 
will induce continuous inflammation and excitation of a primary nociceptive neuron, as a result, spinal cord neuron will be sensitized causing chronic pain. Nerve damage will stimulate the immune cascades as a response to inflammation and oxidative stress that plays an important role in initiating and maintaining acute or chronic neuropathic pain [8]. Glial cells also stimulated as a result of the undertreated nerve damage. Evidence showed that oxidative stress and cyclooxygenase-2 (COX-2) were contributed in the pathophysiology of neuropathic pain [9], [10] Nerve damage will also initiate the formation of reactive oxygen species (ROS), reactive nitrogen species, and free radicals that induce the oxidative stress. Oxidative stress results from the imbalance between prooxidant and antioxidant. Antioxidants are available endogenously as a cellular defense mechanism or acquired exogenously from the diet [11].

In particular, microglia and astrocyte in the dorsal horn of spinal cord play an important role in chronic pain by several neuronal transmission processes including upregulation of pro-inflammatory factors. Activated microglia will show the increase of $\mathrm{P} 2 \mathrm{X} 4$ and $\mathrm{P} 2 \mathrm{X} 7$ receptors expression [12], [13]. After nerve damage, adenosine 5"-triphosphate (ATP) is released to extracellular space from undamaged neuron, damaged neuron, or dead neuron which acts as an important extracellular signal molecule. The rapid action of extracellular ATP is mainly mediated by purinergic $\mathrm{P} 2 \mathrm{X}$ receptors which also act as a ligand-gated ion channel on the cell surface including microglia [14]. This pathway has a potential to be inhibited and can be considered in the prevention and management of neuropathic pain [12].

Anthocyanidin is one of the flavonoids that have been known as the potent antioxidant [15]. Anthocyanin is a heterocyclic flavonoid that is composed of two or three moieties-aglycone anthocyanidins, sugar, and acyl acid. Anthocyanin mainly found in fruits but also available in vegetables, roots, tubers, legumes, and cereals [16]. Anthocyanin effect in pain management has generated satisfactory results. A previous in vitro study found that anthocyanin extracted from cherry tart (Prunus cerasus L.) has the ability as a potent anti-inflammatory and antioxidant compared to other drugs. Anthocyanin that was isolated from tart cherry significantly inhibits lipid peroxidase and shows antiinflammatory activity [17]. As this previously described evidence of anthocyanin, the investigators want to conduct further study to evaluate the anthocyanin effects on inflammation and free radicals, including the characteristics of neuropathic pain caused by peripheral nerve damage. The aim of this study was to determine the effects of anthocyanin water extracts derived from Balinese cultivar of purple sweet potato (PSP) versus placebo on malondialdehyde (MDA) and prostaglandin E2 (PGE2) levels, and neuropathic pain-associated behavior among male Wistar rats with peripheral nerve injury as a result of chronic constriction injury $(\mathrm{CCl})$.

\section{Methods}

\section{Study design}

This was a randomized post-test only control group study. All rats initially underwent peripheral nerve injury induction by means of $\mathrm{CCl}$ before being randomly selected as subjects followed by random allocation to either the treatment or control group. Rats in the treatment group received $0.9 \%$ saline solution administered through nasogastric tube once a day for 28 days, whereas those in the control group received water extracts derived from PSP containing anthocyanin $140 \mathrm{mg} / \mathrm{mL}$ with equivalent dose of $400 \mathrm{mg} / \mathrm{kg}$ body weight/day also administered through nasogastric tube once a day for 28 days calculated anthocyanin dose was based on previous study by Tall et al. [16] Neuropathic pain-associated behavior comprising mechanical allodynia and cold allodynia were evaluated before surgery for $\mathrm{CCl}$, day $1,7,14,21$, and 28 post-surgery. After treatment period ended, all rats were euthanized by pentobarbital injection and collected for its blood, ligated peripheral nerve, and spinal cord segment L4-6. The samples were then measured for serum MDA and peripheral nerve PGE2 levels. Ultimately, all data were analyzed statistically.

\section{Animals}

As many as, 18 Wistar rats with the following criteria were allocated for each group: (1) Wistar albino rat, (2) male sex, (3) 8-9 weeks old, (4) weighing 200-300 g, (5) derived from the same parental lineage, and (6) able to eat and drink normally. All rats were derived from the Laboratory of Pharmacology Faculty of Medicine Udayana University. Rats which fulfilled the aforementioned inclusion criteria were randomly allocated to either treatment or control group, preceded by randomization procedure. All rats were placed in an individual cage made of PVC measuring $40 \times 30$ $\times 20 \mathrm{~cm}$ with dry hay placed as floor mat, maintained on a standard light cycle (lights on between 800 and $2000 \mathrm{~h}$ ), had free access to food and water. Cage's wall and floor were constantly inspected for its sanitariness and floor mat was replaced at least once a week. All rats were handled with care by professional personnel who were responsible for organizing and documenting job description and schedule, amount of food and liquid consumed, and weighing the rats. Rats were left on the cage for 1 week before $\mathrm{CCl}$ procedure was conducted. All experimental procedures were approved by the Ethical Commission and Scientific Coordinator for Healthcare Research Faculty of Medicine Udayana University (ethical approval number: 1619/UN.14.2/ $\mathrm{KEP} / 2017$ ) and were conducted in compliance with the WMA Statement on Animal Use in Biomedical Research. 


\section{CCl induction procedure}

The surgical procedure began by shaving the mice in the lumbar area, subsequently cleaned with cotton and detergent solution, swabbed with $70 \%$ alcohol and Povidone-iodine, respectively. Incision was performed in a longitudinal direction, parallel to the vertebral column along $1.5 \mathrm{~cm}$, which was made $0.5 \mathrm{~cm}$ below the pelvis. On visibility access to the muscles in the region, femoral biceps was separated from superficial gluteus muscle, by which sciatic nerve was visible. The nerve was then isolated and ligated in four segments with a distance of $1 \mathrm{~mm}$ each, using 4.0 chromic catgut (Figure 1a). The surgical wound was then closed layer by layer and finally stapled at the outermost layer to prevent wound dehiscence due to rat biting (Figure 1b). Topical antibiotic was applied on the affected wound to prevent infection.

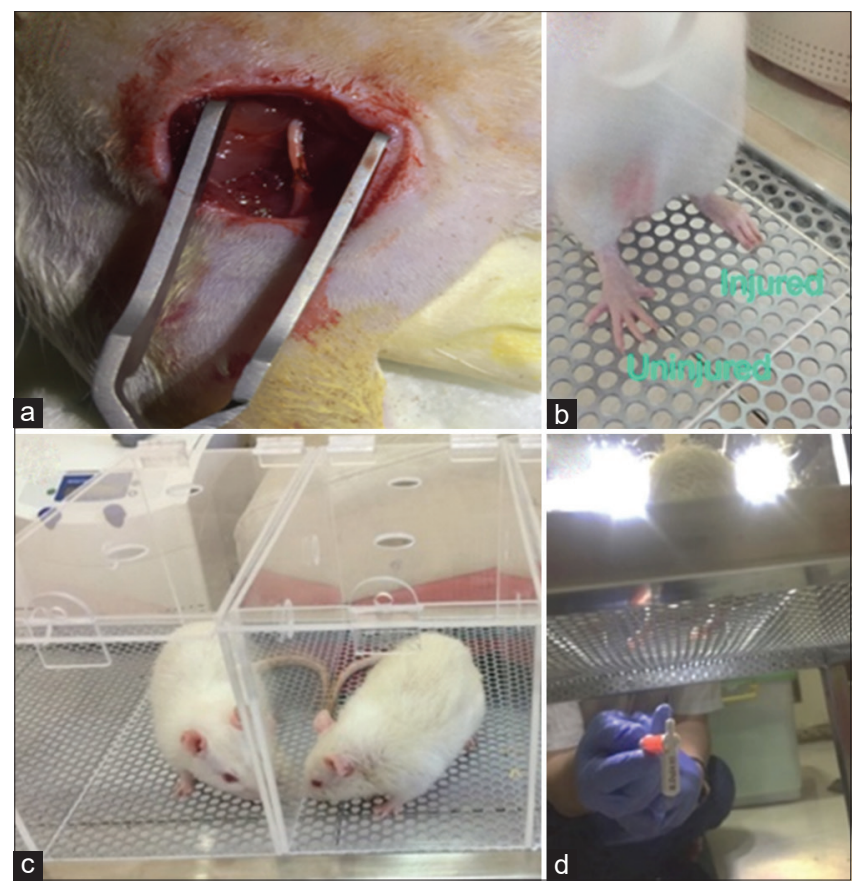

Figure 1: (a) Loose ligation on the affected sciatic nerve. (b) Injured versus uninjured limb post-surgery. (c) All rats were placed on individual cages made of plexiglass with wired floor. (d) Evaluation of mechanical allodynia using Von Frey monofilament

\section{Randomization}

After $\mathrm{CCl}$ induction was done, all rats $(\mathrm{n}=36)$ were placed in individual cages. The samples were then randomized using simple random sampling method, in which samples were taken one-by-one by a human caregiver with enclosed eyes and then put into a new individual cage. As many as, 18 rats were each allocated into treatment and control groups.

\section{PSP water extracts}

Water extracts of PSP were conducted at the Laboratory of Agriculture Product Technology
Udayana University by the following steps. Fresh PSPs obtained from farmers were rinsed until clean and peeled. It then was sliced transversely with a thickness of $2-2.5 \mathrm{~cm}$ and mixed with clean water with a ratio of $1 \mathrm{~kg}$ of PSP to $1 \mathrm{~L}$ of water. The mixture was then blended using a juicer and filtered by three-layered cotton filter. The filtered solution was boiled for $30 \mathrm{~min}$ for sterilization. The anthocyanin content derived from the corresponding solution was $140.23-147.0 \mathrm{ng} / \mathrm{mL}$ as measured using spectrophotometry and stated formally in a letter numbered 145/AN/Lab/FTP/XII/2015 [18]. PSP water extract with anthocyanin dose of $400 \mathrm{mg} /$ $\mathrm{kg}$ body weight was given immediately after the $\mathrm{CCl}$ surgical procedure.

\section{evaluation \\ Neuropathic pain-associated behaviors}

Neuropathic pain-associated behaviors were assessed based on the evaluation of mechanical allodynia and cold allodynia.

\section{Mechanical allodynia}

The evaluation was conducted before surgery, days $1,7,14,21$, and 28 post-CCI induction. Mechanical allodynia was performed as followed. Rats were placed on a $20 \times 20 \times 40 \mathrm{~cm}$ plexiglass with square pattern metal wire (Figure 1c). Rats were given $15 \mathrm{~min}$ free time for the purpose of adaptation and grooming. Mechanical allodynia was in turn evaluated using Von Frey monofilament 4.0, $6.0,8.0,10.0,15.0$, and $26.0 \mathrm{~g}$. Monofilament was applied vertically on the rat's plantar surface at the affected $\mathrm{CCl}$ limb, beginning with the smallest to the biggest monofilament size until leg withdrawal was observed (Figure 1d). The result was positive if there was a visible leg withdrawal. The test was repeated for 5 times for each of the filament with an interval of 2-3 s. Paw withdrawal threshold was positive if rats responded minimally three out of five examinations. Monofilament use was limited to $60 \mathrm{~g}$ to prevent injury) [19].

\section{Cold allodynia}

Cold allodynia was evaluated using acetone drops test. The affected $\mathrm{CCl}$ limb was sprayed using $0.1 \mathrm{~mL}$ acetone by means of a plastic syringe. In rats with no nerve injury, there should be omission of the stimuli or mild and transient paw withdrawal. However, abnormal responses including licking, shivering, or rubbing of the affected limb and the duration between the first time rat's limb was sprayed and the observable abnormal response(s) (also called paw withdrawal latency) was recorded. Test was limited to $20 \mathrm{~s}$ to prevent tissue injury [20]. 


\section{Euthanasia}

Rats were euthanized on day 28 post- $\mathrm{CCl}$ through lethal dose of pentobarbital $(100 \mathrm{mg} / \mathrm{kgBB}) \mathrm{ip}$. Subsequently, all samples were collected for its blood and ligated peripheral nerve to be analyzed in the laboratory.

\section{MDA levels measurement}

MDA levels were measured using TBARS method. Collected blood was initially mixed with EDTA to prevent coagulation. The blood was centrifuged at $2000 \times g$ for $10 \mathrm{~min}$ on temperature of $4^{\circ} \mathrm{C}$. Plasma layer was extracted deliberately and kept on ice if done on the same day or freezed to $-70^{\circ} \mathrm{C}$ if to be kept for up to 30 days. Plasma can be measured without dilution. Each of the specific reagents was added to the glass tube filled with plasma and mixed well, waited for $20 \mathrm{~min}$ at room temperature to let the chemical reaction occurs. $1.5 \mathrm{~mL}$ of solution was used for reading at $532 \mathrm{~nm}$. Pink color was stable for several hours at room temperature. Total MDA levels were measured by heating the solution at $63^{\circ} \mathrm{C}$ for $30 \mathrm{~min}$ according to standard curve (Oxford Biomedical Research).

\section{PGE2 levels measurement}

The samples from peripheral nerve was immediately stored at $20^{\circ} \mathrm{C}$ until examination was performed. PGE2 levels were measured based on ELISA method using PGE2 High Sensitivity Immunoassay Kit from R\&D Systems (Minneapolis, MN, USA). All reagents and samples were collected under room temperature before usage. All samples and standards were recommended to be tested under duplication. Total activity tube (TA), non-specific binding (NSB), maximum binding (BO), and empty substrate must be run on every tests as quality controls for every test. All reagents, standard procedure, and samples were prepared. All microplate strips in excess were discarded, put into the foil with drying package, and resealed. Tubes for TA and empty substrate were stored. $150 \mu \mathrm{L}$ of test buffer solution (CCM) was added on NSB tube, $100 \mu \mathrm{L}$ of test buffer solution (or CCM) was added on zero standard tube (B0), and $100 \mu \mathrm{L}$ of standard or sample solution was added to the remaining tubes. $50 \mu \mathrm{L}$ of PGE2 HS conjugate was then added on every tubes (excluding TA and blank substrate tube), followed with $50 \mu \mathrm{L}$ of PGE2 HS antibody solution on each tube (excluding NSB, TA, and blank substrate tube). All tubes were sealed with the pre-existing paper and incubated for $18-24 \mathrm{~h}$ at $2-8^{\circ} \mathrm{C}$. The solution was aspirated and tubes were rinsed with rinse buffer solution $(400 \mu \mathrm{L})$ through sprayed bottle or dispenser manifold, repeated twice with total three rinses. Complete rinse on each step is necessary to ensure good results. After the last rinse, rinse buffer was discarded with aspiration or pouring out. $5 \mu \mathrm{L}$ of PGE2 HS conjugate was added on TA tube. $200 \mu \mathrm{L}$ of pNPP substrate was added on all tubes and sealed with pre-existing paper, incubated for an hour with temperature $37^{\circ} \mathrm{C}$. $200 \mu \mathrm{L}$ of stop solution was subsequently added to all tubes. Optical density on each tube was measured using micro template adjusted at $405 \mathrm{~nm}$ wavelength with correction between 570 and $590 \mathrm{~nm}$.

\section{Statistical analysis}

Data analyses were performed by the following steps. Descriptive statistics was used to describe baseline characteristics of the two groups and its frequency distribution for every variable. Normality test was done using Shapiro-Wilk test due to the relatively small sample size. $p$ value of more than 0.05 was defined as normally distributed, and vice versa. The difference between MDA and PGE2 levels, and neuropathic pain behavior on both groups was tested using independent t-test when data were normally distributed or Mann-Whitney test on abnormally distributed data. $p<0.05$ was deemed statistically significant.

Data were gathered from 34 samples which survived until the end of observation period (day 28). One sample from each group was excluded because of outlier data. All data from 32 samples were statistically analyzed.

\section{Results}

\section{Surgical procedure for $\mathrm{CCl}$ induction}

This study was conducted between September 2017 and May 2018 at the Laboratory of Pharmacology, Integrated Biomedical Laboratory, and Anatomical Pathology Department from Faculty of Medicine Udayana University, Denpasar. All rats underwent surgical procedure for $\mathrm{CCl}$ induction as a form of peripheral nerve injury. Four loose ligations were done on the sciatic nerve (Figure $1 \mathrm{a}$ ). $\mathrm{CCl}$ was deemed successful if the affected limb demonstrated genu articular flexion with toes abduction (Figure 1b).

\section{Rats follow-up}

As many as, 18 rats were allocated to each group (treatment and control) and each rat was placed on an individual case as previously described. One rat from treatment and control group died 10 and 6 days after $\mathrm{CCl}$, respectively, leaving a total of 34 samples until the end of observation period.

Serum MDA levels in both treatment and control groups were normally distributed. PGE2 levels in the treatment group and control group also showed normal data distribution ( $p>0.05)$. Meanwhile, data of 
mechanical allodynia from both treatment and control group showed abnormal data distribution $(p<0.05)$, while cold allodynia in treatment and control group showed normal data distribution $(p>0.05)$.

\section{MDA levels were significantly lower in the treatment versus control group}

In the treatment group, the mean serum MDA levels were $0.110 \pm 0.042 \mu \mathrm{mol}$ lower than in the control group, i.e., $0.226 \pm 0.032 \mu \mathrm{mol} / \mathrm{L}$. There was a significant difference in mean MDA content of $0.116 \mu \mathrm{mol}$ in both groups $(p<0.001)$ (Table 1$)$. These results indicated that PSP water extracts lowered oxidative stress in the treatment group compared to the control group after peripheral nerve injury.

\section{PGE2 levels were significantly lower in the treatment versus control group}

PGE2 levels on the ligated sciatic nerve of treatment group were lower than that of control. In the treatment group, mean PGE2 levels were $0.342 \pm 0.096 \mathrm{ng} / \mathrm{mL}$ lower than control group, i.e., 0.431 $\pm 0.061 \mathrm{ng} / \mathrm{ml}$. There was a significant difference of $0.089 \mathrm{ng} / \mathrm{mL}$ in both groups $(p<0.05)$ (Table 1). These results indicated that sweet potato water extracts lowered the degree of inflammation among treatment group as opposed to control group after peripheral nerve injury.

\section{Mechanical allodynia was significantly ameliorated among treatment versus control group on day 7 thereafter}

The observations of mechanical allodynia behavior were performed before the surgical procedure for $\mathrm{CCl}$ induction, on days 1, 7, 14, 21, and 28 postsurgery. Normality test showed that mechanical allodynia was not normally distributed, thus MannWhitney test was used. Mechanical allodynia did not differ significantly before $\mathrm{CCl}$ procedure and shortly thereafter. However, treatment group was shown to have milder symptom after day 7 as marked by the ability to tollerate larger Von Frey monofilament when compared with control group (26 g vs. $10 \mathrm{~g}$ ) with statistical significance $(p<0.001)$. This was also seen on day 14 , wherein median von frey monofilament on treatment group was significantly larger than control (15 g vs. $10 \mathrm{~g})$ with statistical significance $(p<0.001)$. On day 21 , rats in the treatment group still able to tollerate larger von frey monofilament when compared with control group (10 g vs. $8 \mathrm{~g}$ ) with statistical significance $(p<0.005)$. The effect persisted even until day 28, in which treatment group was able to tollerate larger monofilament (15 g vs. $10 \mathrm{~g}$ ) with statistical significance $(p<0.001)$.

On day 7 post-surgery, monofilament size in both groups was similarly decreased, whereas median monofilament size in treatment group was significantly greater than control. This phenomenon continued until day 14 ( $p<0.001)$ (Figure 2a). On day 21, decrease in mean monofilament size still occurred in both groups with significant difference although the mean size reduction was not as high as observed on day 7 and day 14 ( $p<0.05)$. In addition, there was no observable decrease of monofilament size on day 28 in the treatment group, while in the control group there was a decrease in mean monofilament size and this difference was statistically significant $(p<0.001)$.

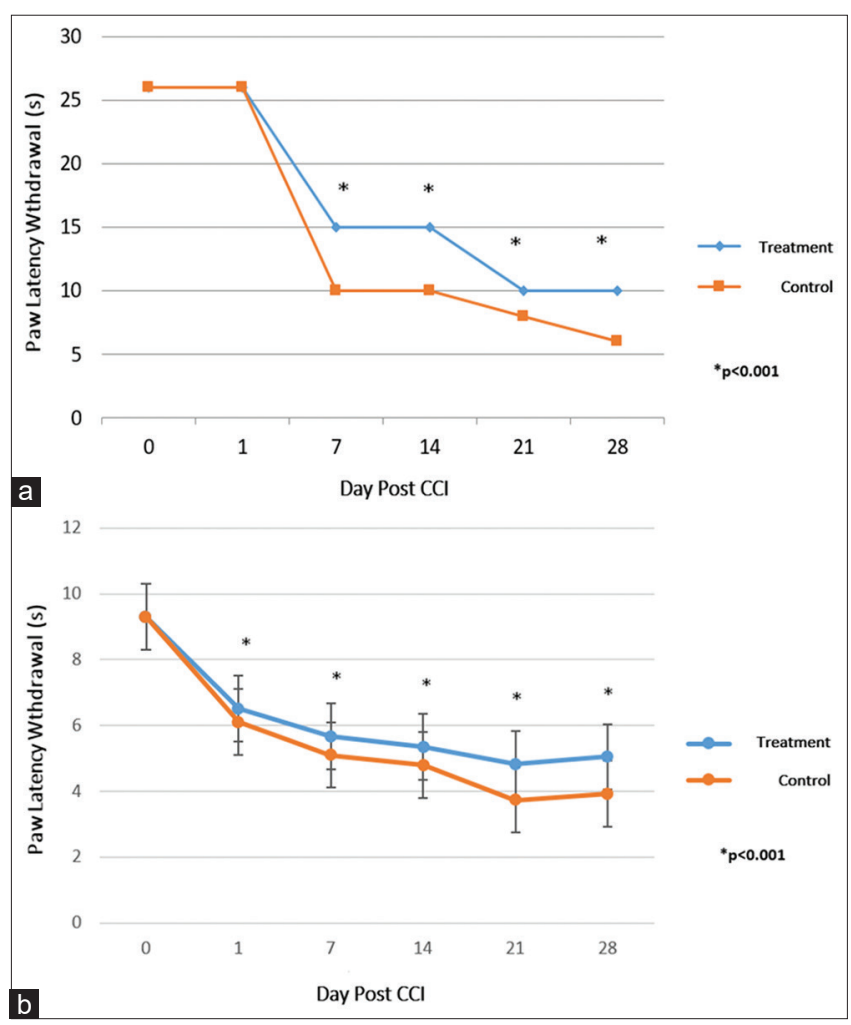

Figure 2: Differences between (a) mechanical allodynia and (b) cold allodynia among both groups

All of these results indicated that mechanical allodynia behavior can readily be assessed since day 7 post-CCl induction and persisted until day 28. PSP water extracts administration was proven to ameliorate mechanical allodynia behavior characterized by greater reduction of average monofilament size than control group.

Table 1: Mean difference and significance of MDA serum and peripheral nerve's PGE2 levels between treatment and control group

\begin{tabular}{|c|c|c|c|c|c|c|}
\hline Parameter & Groups & Mean \pm SD & Range (min-max) & Mean difference & $95 \% \mathrm{Cl}(\min -\max )$ & $p$ value \\
\hline MDA serum levels $(\mu \mathrm{mol})$ & Treatment & $0.291 \pm 0.046$ & $0.206-0.365$ & 0.102 & $0.065-0.140$ & $<0.001^{*}$ \\
\hline Peripheral nerve's PGE2 levels ( $\mathrm{ng} / \mathrm{ml})$ & $\begin{array}{l}\text { Control } \\
\text { Treatment }\end{array}$ & $\begin{array}{l}0.394 \pm 0.057 \\
0.342 \pm 0.096\end{array}$ & $\begin{array}{l}0.325-0.515 \\
0.141-0.466 \\
0.278-0.528\end{array}$ & 0.089 & $0.031-0.147$ & $0.004^{*}$ \\
\hline
\end{tabular}




\section{Cold allodynia was significantly} ameliorated among treatment versus control group on day 1 thereafter

Before $\mathrm{CCl}$ procedure, there was no significant difference of paw withdrawal latency between treatment and control group. However, cold allodynia was significantly ameliorated as early as day 1 among treatment when compared with control group as shown by greater paw withdrawal latency among the former group (6.51 \pm 0.15 vs. $6.11 \pm 0.18$, respectively), thus indicating that treatment subjects were able to better withstand cold exposure than of control group (Figure 2b). The difference persisted to days 7, 14, 21, and 28 after $\mathrm{CCl}$ with treatment group demonstrating consistently greater latency time than those of control group with statistical significance.

The average paw withdrawal latency on day 1 after $\mathrm{CCl}$ in both groups altogether showed a decrease value, although the amount was greater significantly on the treatment group than control. The difference persisted on days $7,14,21$, and 28 with statistical significance $(p<0.001)$. Paw withdrawal latency in both groups was similarly decreased, where the mean time of withdrawal in the treatment group was significantly greater than the control. These results indicated that cold allodynia behavior was readily observable from day 1 to day 28 post-CCl. It can be concluded, therefore, that the administration of PSP water extracts among treatment group ameliorated cold allodynia behavior to a greater extent than the placebo.

\section{Discussion}

Anthocyanin had been extensively studied for its antioxidant properties. However, to the best of our knowledge, there has been no study using anthocyanin derived from PSP to suppress oxidative stress after peripheral nerve injury. Among the neuropathic pain models, the $\mathrm{CCl}$ model has been widely used because it produces tactile alodinia that resembles observable conditions in patients with neuropathic pain [21]. CCI caused significant oxidative damage to the sciatic nerve with indicators of increased MDA and nitric oxide (NO) concentrations and reduction in GSH levels, besides inciting inflammation through increasing proinflammatory cytokines production and secretion (including interleukin [IL]-6, IL-1 $\beta$, and tumor necrosis factor-alpha) [22].

It is clear that ROS is involved in the formation and maintenance of neuropathic pain [23]. It was demonstrated herein that the administration of anthocyanin after peripheral nerve injury was able to reduce oxidative stress as indicated by marked reduction of MDA levels. This result was similar to previous study which linked the use of anthoyanin from various natural sources to suppress oxidative stress (Jawi, 2008; Bakar, 2010) [24], [25]. A study by Kaulaskar et al. [23] showed that the administration of naringenin with doses of 25 and $50 \mathrm{mg} / \mathrm{kg}$ on rats induced with $\mathrm{CCl}$ was able to reduce MDA levels and increase antioxidant GSH. The exerts its antioxidant effects through several mechanisms, i.e.: (1) To prevent the formation of free radicals by inhibiting the enzyme xanthine oxidase and metal transition; (2) inhibits free radicals which damage target cells (donates electrons and captures free radicals); (3) inhibit the propagation of oxidative reactions (chain breaking antioxidant); and (4) reinforces the cell's antioxidant capacity (sparing effect) and induces the expression of endogenous antioxidants [26].

We also found that anthocyanin markedly lower PGE2 levels as one of the important indicators for inflammation. Anthocyanins have consistently been shown to have anti-inflammatory properties, proven by their ability to: (1) Decrease concentration and expression of pro-inflammatory mediators while increasing anti-inflammatory molecules; (2) diluting inducible nitric oxide synthase (iNOS) activity and thus decrease the expression of NO; and (3) reduces COX-2 activity and thus decreases PGE2 expression. Most of these effects were related to inhibition of translocation and activation of transcription factors which play a key role in the initiation and maintenance of inflammation (Vendrame and Klimis-Zacas, 2015) [27]. In fact, the previous study has robustly demonstrated the antiinflammatory effects modulated by anthocyanin, including inhibition of pro-inflammatory enzymes (e.g., COX-2, lipoxygenase, and iNOS) as well as inhibition of various transcription factors (mitogen-activated protein kinase, protein kinase $\mathrm{C}$, and nuclear factor kappa B) [28].

PGE2 is well-associated in the pathogenesis of peripheral nerve injury and neuropathic pain. For example, PGE2 and its receptors (EP1 and EP4) were shown to be upregulated 2-4 weeks after peripheral nerve injury in animal model [29]. It was also able to increase peripheral nociceptor response through binding with TRPV1 and SCN10A receptors, those of which activated leads to an increase of peripheral nociceptors sensitization and triggers nociceptive impulse propagation along the peripheral nerve [30]. The reduction of PGE2 levels by means of anthocyanin could, therefore, serve as a potential treatment avenue to inhibit peripheral nerve sensitization and ultimately minimizing central sensitization.

The administration of anthocyanin was also proven to significantly ameliorate peripheral nerve injury-induced neuropathic pain behavior of all qualities, i.e., mechanical allodynia and cold allodynia. Indeed, this study confirmed the previous findings in which anthocyanin derived from tart cherry with dose of $400 \mathrm{mg} / \mathrm{kg}$ body weight was able to suppress inflammation-induced mechanical hyperalgesia [16]. 
The exact mechanisms underlying these findings have not been fully elucidated, but it is prudent to assume that it was at least in part due to its antioxidant and anti-inflammatory properties. It is congruent with current knowledge of the pathogenesis of neuropathic pain, in which inflammation, nerve growth factors, and other algogenic substances on the damaged nerves contribute to synaptic and neuronal plasticity, all of which leads to neuronal hyperexcitability and neuropathic pain [31].

Cold allodynia is a frequent clinical complaint in patients with neuropathic pain. The mechanism underlying the occurrence of cold alodinia is still not fully known. A study showed a significant decrease in foot withdrawal time on cold metal plate. Activation of $C$ nerve fibers mediates the occurrence of cold allodynia [32]. A recent study by Lippoldt et al. [33] proves that cold allodynia induced by inflammation, neurological injury, and chemotherapy was exclusively mediated by a molecular pathway that neutralizes antibodies against the glial cell line-derived neurotrophic factor family of receptors (GFR $\alpha 3$ ).

This study proved that the water extracts of Balinese cultivar of PSP with anthocyanin content of $400 \mathrm{mg} / \mathrm{kg} \mathrm{BW/day} \mathrm{can} \mathrm{suppress} \mathrm{the} \mathrm{neuropathic}$ pain behavior compared to control in $\mathrm{CCl}$-induced neuropathic pain model in rats.

\section{Conclusion}

Anthocyanin derived from water extracts of Balinese cultivar of PSP in a dose of $400 \mathrm{mg} / \mathrm{kg} \mathrm{BW} /$ day was significantly able to suppress free radicals (reduced MDAlevels), inflammation (PGE2 levels), and peripheral nerve injury-induced neuropathic pain behaviors (mechanical allodynia and cold allodynia). This study merits further investigation in the use of anthocyanin for ameliorating neuropathic pain, potentially as an adjunctive treatment incorporated into a clinical trial.

\section{Acknowledgment}

The authors would like to thank Prof. Bakta, Prof. Mantik, Prof. Manuaba, Prof. Lucas, and Dr. Purwa for their contribution as dissertation jury members. The authors also thanked Dr. Niryana, PhD and Dr. Soejitno for their contribution in this research and manuscript. The authors also thanked The Ministry of Education of Indonesia for the research grant.

\section{References}

1. IASP. Pain terms, a current list with definitions and notes on usage. In: Classification of Chronic Pain, Part III. $2^{\text {nd }}$ ed. Seattle: IASP Press; 1994.

2. Purwata $T$, Anggraini $H$, Anwar $Y$, Amir D, Asnawi $C$ Rahmawati $\mathrm{D}$, et al. Characteristics of neuropathic pain in Indonesia: A hospital based national clinical survey. Neurol Asia. 2015;20(4):389-94

3. Smith BH, Torrance N. Epidemiology of neuropathic pain and its impact on quality of life. Curr Pain Headache Rep. 2012;16(3):191-8. https://doi.org/10.1007/s11916-012-0256-0 PMid:22395856

4. Ciaramitaro P, Mondelli M, Logullo F, Grimaldi S, Battiston B, Sard A, et al. Traumatic peripheral nerve injuries: Epidemiological findings, neuropathic pain and quality of life in 158 patients. J Peripher Nerv Syst. 2010;15(2):120-7. https://doi. org/10.1111/j.1529-8027.2010.00260.x

PMid:20626775

5. Lustosa AA, Nogueira LT, Pedrosa JI, Teles JB, Campelo V. The impact of leprosy on health-related quality of life. Rev Soc Bras Med Trop. 2011;44(5):621-6. https://doi.org/10.1590/ s0037-86822011000500019 PMid:22031079

6. Cohen SP, Mao J. Neuropathic pain: Mechanisms and their clinical implications. Br Med J. 2014;348.

PMid:24500412

7. Akkurt HE, Gumus H, Goksu H, Odabasi OF, Yilmaz H. Gabapentin treatment for neuropathic pain in a child with sciatic nerve injury. Case Rep Med. 2015;2015:873157. https://doi. org/10.1155/2015/873157

PMid:26346828

8. Jo D, Chapman CR, Light AR. Glial mechanisms of neuropathic pain and emerging interventions. Korean $\mathrm{J}$ Pain. 2009;22(1):1-15. https://doi.org/10.3344/kjp.2009.22.1.1

9. Khali Z, Liu T, Helme RD. Free radicals contribute to the reduction in peripheral vascular responses and the maintenance of thermal hyperalgesia in rats with chronic constriction injury. Pain. 1999;79(1):31-7. https://doi.org/10.1016/s0304-3959(98)00143-2 PMid:9928773

10. Ma W, Quirion R. Does COX2-dependent PGE2 play a role in neuropathic pain? Neurosci Lett. 2008;437(3):165-9. https://doi. org/10.1016/j.neulet.2008.02.072

PMid: 18434017

11. Oyenihi AB, Ayeleso AO, Mukwevho E, Masola B. Antioxidant strategies in the management of diabetic neuropathy. Biomed Res Int. 2015;2015:15. https://doi.org/10.1155/2015/515042 PMid:25821809

12. Tsuda $M$, Tozaki-Saitoh $H$, Inoue $K$. $P 2 X 4 R$ and $P 2 X 7 R$ in neuropathic pain. Wiley Interdiscip Rev Membr Transp Signal. 2012;1(4):513-21. https://doi.org/10.1002/wmts.47

13. Beggs $S$, Trang $T$, Salter MW. $P 2 X 4 R+$ microglia drive neuropathic pain. Nat Neurosci. 2012;15(8):1068-73. https://doi. org/10.1038/nn.3155

PMid:22837036

14. Jiang LH. P2X receptor-mediated ATP purinergic signaling in health and disease. Cell Health Cytoskeleton. 2012;4:18. https://doi.org/10.2147/chc.s27196

15. Erdman JW Jr., Balentine D, Arab L, Beecher G, Dwyer JT, Folts $\mathrm{J}$, et al. Flavonoids and heart health: Proceedings of the ILSI North America flavonoids workshop, May 31-June 1, 2005, Washington, DC. J Nutr. 2007;137(1):718S-37. https://doi. org/10.1093/jn/137.3.718s 


\section{PMid:17311968}

16. Tall JM, Seeram NP, Zhao C, Nair MG, Meyer RA, Raja SN Tart cherry anthocyanins suppress inflammation-induced pain behavior in rat. Behav Brain Res. 2004;153(1):181-8. https://doi. org/10.1016/j.bbr.2003.11.011

PMid:15219719

17. Wang H, Nair MG, Strasburg GM, Booren AM, Gray JI. Nove antioxidant compounds from tart cherries (Prunus cerasus). J Nat Prod. 1999;62(1):86-8. https://doi.org/10.1021/np980268s PMid:9917288

18. Lee J, Rennaker C, Wrolstad R. Correlation of two anthocyanin quantification methods: HPLC and spectrophotometric methods. Food Chem. 2008;110:782-6. https://doi.org/10.1016/j. foodchem.2008.03.010

19. Amin B, Abnous K, Motamedshariaty V, Hosseinzadeh $\mathrm{H}$. Attenuation of oxidative stress, inflammation and apoptosis by ethanolic and aqueous extracts of Crocus sativus L. Stigma after chronic constriction injury of rats. An Acad Bras Cienc. 2014;6(4):1821-32. https://doi. org/10.1590/0001-3765201420140067 PMid:25590719

20. Bhardwaj H, Muthuraman A, Hari K, Navis S. Antioxidative and anti-inflammatory potentials of ambroxol in ameliorating vincristine induced peripheral neuropathic pain in rats. J Neuroinfect Dis. 2016;7(1):7. https://doi. org/10.4172/2314-7326.1000202

21. Bennett GJ, Xie YK. A peripheral mononeuropathy in rat that produces disorders of pain sensation like those seen in man. Pain. 1988;33(1):87-107. https://doi. org/10.1016/0304-3959(88)90209-6

PMid:2837713

22. Chanchal SK, Mahajan UB, Siddharth S, Reddy N, Goyal SN Patil PH, et al. In vivo and in vitro protective effects of omeprazole against neuropathic pain. Sci Rep. 2016;6:30007. https://doi. org/10.1038/srep30007

23. Kaulaskar S, Bhutada P, Rahigude A, Jain D, Harle U. Effects of naringenin on allodynia and hyperalgesia in rats with chronic constriction injury-induced neuropathic pain. Zhong $\mathrm{Xi} \mathrm{Yi}$ Jie He Xue Bao. 2012;10(12):1482-9. https://doi.org/10.3736/ jcim20121223 PMid:23257145

24. Jawi M, Suprapta DN, Subawa AA. Ubi jalar ungu menurunkan kadar MDA dalam darah dan hati mencit setelah aktivitas fisik maksimal. J Vet. 2008;9(2):65-72.

25. Bakar OA. Pemberian Ekstrak Kulit Terung Ungu Menghambat Peningkatan MDA Dalam Darah Tikus Wistar Yang Diinduksi Aktivitas Fisik Maksimal, Thesis. Denpasar: Universitas Udayana; 2010.

26. Kelsey NA, Wilkins HM, Linseman DA. Nutraceutical antioxidants as novel neuroprotective agents. Molecules. 2010;15(11):7792814. https://doi.org/10.3390/molecules15117792 PMid:21060289

27. Vendrame S, Klimis-Zacas D. Anti-inflammatory effect of anthocyanins via modulation of nuclear factor-kB and mitogenactivated protein kinase signaling cascades. Nutr Rev. 2015;73(6):348-58. https://doi.org/10.1093/nutrit/nuu066 PMid:26011910

28. Serafini M, Peluso I, Raguzzini A. International immunonutrition workshop session 1: Antioxidants and the immune system flavonoids as anti-inflammatory agents. Proc Nutr Soc. 2010;69:6.

29. Kawabata A. Prostaglandin E2 and pain--an update. Biol Pharm Bull. 2011;34(8):1170-3. https://doi.org/10.1248/bpb.34.1170 PMid:21804201

30. Bhave G, Zhu W, Wang H, Brasier DJ, Oxford GS, Gereau RW. cAMP-dependent protein kinase regulates desensitization of the capsaicin receptor (VR1) by direct phosphorylation. Neuron. 2002;35(4):721-31. https://doi.org/10.1016/ s0896-6273(02)00802-4 PMid:12194871

31. Jensen TS, Finnerup NB. Allodynia and hyperalgesia in neuropathic pain: Clinical manifestations and mechanisms. Lancet Neurol. 2014;13(9):924-35. https://doi.org/10.1016/ s1474-4422(14)70102-4 PMid:25142459

32. Tanimoto-Mori S, Nakazato-Imasato E, Toide K, Kita Y Pharmacologic investigation of the mechanism underlying cold allodynia using a new cold plate procedure in rats with chronic constriction injuries. Behav Pharmacol. 2008;19(1):85-90. https://doi.org/10.1097/fbp.0b013e3282f3d0a3

PMid:18195599

33. Lippoldt EK, Ongun S, Kusaka GK, McKemy DD. Inflammatory and neuropathic cold allodynia are selectively mediated by the neurotrophic factor receptor GFRalpha3. Proc Natl Acad Sci U S A. 2016;113(16):4506-11. https://doi.org/10.1073/ pnas. 1603294113 